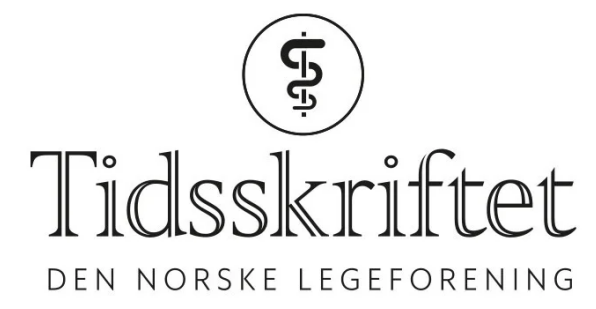

\title{
Utviklingshemmede er fortsatt en pariakaste
}

KRONIKK

\section{TORSTEIN VIK}

torstein.vik@ntnu.no

Torstein Vik er professor emeritus i barnesykdommer ved NTNU. Han er far til en 46 år gammel utviklingshemmet kvinne.

Forfatteren har fylt ut ICMJE-skjemaet og oppgir ingen interessekonflikter.

Det var «bred politisk enighet» om at utviklingshemmede skulle få leve et liv som den gjengse borger da en gjennomtenkt og visjonær reform ble innført i 1991. Arkitekten bak reformen var en lege. 30 år senere har reformen havarert. Er det umulig for utviklingshemmede i Norge å få verdige liv?

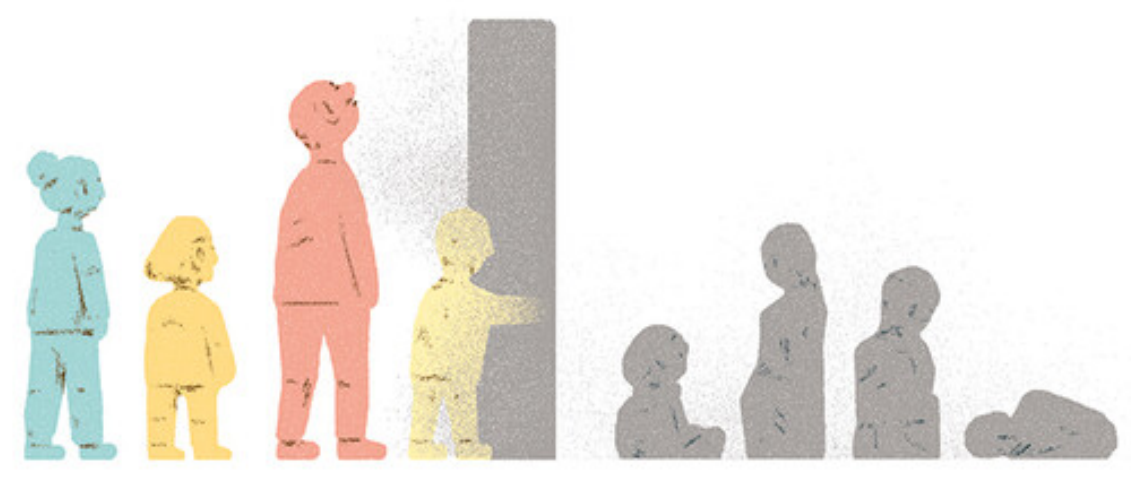


Illustrasjon: Audun Gjerdi

I 1988 vedtok Stortinget en reform som skulle gi mennesker med kognitiv

funksjonsnedsettelse (heretter kalt utviklingshemmede) anledning til å velge hvor og

hvordan de ville bo, anledning til å leve aktive liv og delta i samfunnet som andre mennesker (1). Prinsippene for reformen bygde på to offentlige utredninger, ledet av psykiater Ole Petter Lossius (1925-2007) (2,3). Innføringen startet i 1991. Ansvaret for gjennomføringen ble overført fra fylkeskommunene til kommunene, derav navnet Ansvarsreformen for utviklingshemmede (heretter kalt ansvarsreformen) $(\underline{1}, 4$.).

Reformens hovedmål overlappet godt med målene for habilitering og rehabilitering av mennesker med funksjonshemninger slik de beskrives i den internasjonale klassifikasjonen av funksjon, funksjonshemming og helse (ICF), publisert ti år senere (5), og med FN-konvensjonen om rettigheter til mennesker med nedsatt funksjonsevne (CRPD), vedtatt av FN i $2006(\underline{6})$.

Bortsett fra at de store institusjonene ble nedlagt, noe som var et delmål, og at ansvaret ble overført til kommunene, kom reformen skjevt ut fra start. I år, 30 år etter innføringen, er utviklingen reversert. Utviklingshemmede blir igjen plassert i store, institusjonspregede boligkompleks (7.). Få har meningsfullt arbeid, og mulighetene til å delta i fritidsaktiviteter er svært begrenset (ㅁ). Grunnen til at reformen kom skjevt ut, var at ingen av de gode intensjonene ble rettighetsfestet (9.). Når politikere skal vedta budsjetter, er utviklingshemmedes levekår ikke lenger noen hjertesak.

I 2011 ble det overordnede ansvaret for utviklingshemmedes levekår overført til Kulturdepartementet, som også har ansvar for likestilling (므). Til tross for at omorganiseringen reduserte legenes rolle, er det både historiske, moralske og medisinske grunner til at leger bør ha et særlig ansvar for å få reformen på rett kurs igjen.

\section{Legens rolle - fra humanisme til rasehygiene}

Holdningene til utviklingshemmede var i det kristne Europa frem til 18oo-tallet preget av inhumane holdninger og mangel på respekt (4.). Utviklingshemmede ble betraktet som laverestående mennesker, mindre verdt enn dyr ( $\underline{10})$. Mange ble holdt fastlenket og innelåst sammen med psykisk syke i kjempeinstitusjoner (1ㅡ). Under den franske revolusjonen befridde legen Philippe Pinel (1745-1826) de innestengte fra lenkene, åpnet portene og innførte mer humane holdninger $(\underline{11}, \underline{12})$. En annen fransk lege, Jean Marc Gaspard Itard (1774-1838), var blant de første som startet målrettet opplæring av utviklingshemmede (13). I England gjorde John Langdon Down (1828-1896) et banebrytende arbeid for human behandling, respektfulle holdninger og for opplæring av utviklingshemmede (14.).

\section{«Når politikere skal vedta budsjetter, er utviklingshemmedes levekår} ikke lenger noen hjertesak»

Med fremveksten av eugenikken på slutten av 18oo-tallet bidro leger dessverre til at holdningene endret seg til det verre (15-17.). Rasehygienen ble ansett som viktig for folkehelsen og ble et anerkjent forskningsfelt i USA, England, Tyskland og Skandinavia (므). Noen kjente norske leger som var opptatt av raseteorier og rasehygiene, var blant andre Halfdan Bryn (1864-1933), president i Legeforeningen og preses i Det Kongelige Norske Videnskabers Selskab, forskerekteparet Alette (1873-1951) og Kristian Schreiner (1874-1957) samt Ingeborg Aas (1876-1958), venstrepolitiker, sanitetskvinne og forkjemper for helsestasjoner (15-17.). I USA lobotomerte amerikanske leger John F. Kennedys lett utviklingshemmede søster, Rosemary, i 1941 (18). Lobotomien førte til at hun ble totalt

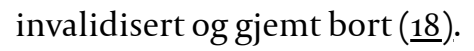


Rasehygienen kulminerte med drapene på funksjonshemmede i Nazi-Tyskland (19.). Likevel

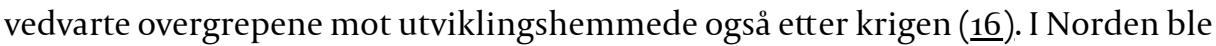
utviklingshemmede utsatt for mishandling, uetiske forskningsfors $ø \mathrm{k} \mathrm{og}$ tvangssterilisering helt frem til 1970-årene $(\underline{4}, \underline{16}, \underline{20})$. Dette skjedde mens de ble samlet og isolert fra den øvrige befolkningen i store institusjoner (4).

\section{Human reform som havarerte}

I 1970- og 80-årene ledet psykiater Ole Petter Lossius arbeidet med to offentlige utredninger $(\underline{2}, 3)$. Konklusjonene i disse var at utviklingshemmede selv burde få velge hvor og hvordan de ville bo, at det ikke var noen grunn til at de skulle isoleres i store institusjoner, at de burde få tilpasset utdanning og arbeid samt tilgang til fritidsaktiviteter som andre borgere. Konklusjonene overlapper imponerende godt med intensjonene i ICF-klassifikasjonen og i CRPD-konvensjonen, som ble publisert 20-30 år senere (5, 6 ). Man kan trygt si at Lossius og hans medarbeidere var meget fremsynte.

\section{"Hovedgrunnen til havariet av ansvarsreformen er at det ikke fulgte rettigheter med de gode intensjonene»}

Utredningene førte til innføringen av ansvarsreformen i 1991 (11). Dessverre gikk det galt helt fra starten, og siden innføringen har en rekke rapporter og offentlige utredninger jevnlig dokumentert at ingen av hovedmålene er oppnådd $(7, \underline{7}, \underline{21})(\underline{21-23})$. I 2006 påviste Helsetilsynet at utviklingshemmede ble utsatt for overgrep og utilbørlig tvang (23). I 2007 publiserte Helsedirektoratet en rapport som stilte spørsmål ved gjennomføringen av reformen (1ㅡ). En NTNU-rapport viste i 2011 at store bofellesskap igjen var blitt vanlige (7.). En ny stortingsmelding i 2012 gav uttrykk for bekymring (르) og førte til en ny offentlig utredning, publisert i 2016 med tittelen På lik linje (모). Denne konkluderte nok en gang med at man var langt unna å nå hovedmålene for reformen (ㅁ). På lik linje har foreløpig bare ført til at man igjen venter på en ny stortingsmelding! Det er god dekning for å hevde at ansvarsreformen var en human reform som havarerte. Hovedgrunnen til havariet er at det ikke fulgte rettigheter med de gode intensjonene.

\section{Pårørende bærer byrdene}

Allerede i 1994/95 advarte legen og juristen Aslak Syse om at uten rettigheter ville reformen havarere og familiene ville måtte «... bære byrdene for en omsorgsreform som skulle komme alle til gode» (9.). Flere kjente forfattere, med egne erfaringer, har siden 2012 beskrevet hvordan livet som foreldre til et utviklingshemmet barn i Norge kan arte seg og hvordan det kan slite på hele familien (24-28). De nevnte utredningene og rapportene, de skjønnlitterære beskrivelsene og også mine egne erfaringer som far har vist at Syse fikk rett.

\section{Uten menneskerettigheter}

I utredningen På lik linje ble levekårene for utviklingshemmede i Norge i 2016 ikke bare målt mot intensjonene i ansvarsreformen, men også mot CRPD-konvensjonen (모). Denne ble ratifisert av Norge i 2013, men er enda ikke innarbeidet i norsk lovverk (29). Målt mot konvensjonen var utviklingshemmedes rettigheter i Norge mangelfulle på hele $15 \mathrm{av}$ punktene (artiklene) (ㅁ). Dette gjaldt både artikler om generelle menneskerettigheter og artikler om alminnelige levekår. På lik linje konkluderte med at Norge ikke oppfyller artiklene som omhandler utdanning (artikkel 24), helse (artikkel 25), habilitering og rehabilitering (artikkel 26), arbeid og sysselsetting (artikkel 27), deltakelse i politisk og 
offentlig liv (artikkel 29) samt deltakelse i kulturliv, fritidsaktiviteter, fornøyelser og idrett (artikkel 30). Alle disse områdene var de sentrale målene i ansvarsreformen og i begge Lossius-utvalgene (1-3).

\section{«Vi som leger har et utvidet ansvar for utviklingshemmedes levekår»}

I mars 2019 kritiserte FNs komité for rettigheter til mennesker med nedsatt funksjonsevne at Norge ennå ikke hadde innarbeidet CRPD-konvensjonen i eget lovverk (29.). Komiteen mente at mangelen på rettigheter var hovedårsaken til mange av de problemene funksjonshemmede i Norge opplever, også de store forskjellene ulik kommunetilhørighet gir (29.). I På lik linje beskrives åtte tiltak for å få ansvarsreformen på fote igjen (모). Det første tiltaket er å innarbeide CRPD-konvensjonen i norsk lovverk. Så sent som i mars i år avviste Stortinget for tredje gang et slikt forslag (30).

\section{Sviktende overordnet styring}

Frem til 2011 lå det overordnede ansvaret for utviklingshemmedes levekår hos Helse- og sosialdepartementet. Da ble ansvaret splittet i sektorer, som helse, utdanning, arbeid, sosial og bolig (ㅁ). Et koordinerende ansvar ble plassert hos likestillingsministeren, som for tiden også er kulturminister. Intensjonen med omorganiseringen var et ønske om å fremheve likestillingsaspektet. Imidlertid beskriver man i På lik linje at denne organiseringen har fungert dårlig fordi det enkelte departements hovedmål har blitt prioritert høyere enn sektoroverskridende likestilling (모). Selv om reformen var i ferd med å havarere i 2011, har oppsplittingen av ansvar og svak overordnet styring bidratt til å sementere havariet.

\section{Både leger og politikere må handle}

Deltakelse og aktive liv er de overordnede målene for all habilitering og rehabilitering av mennesker med funksjonsnedsettelser (5). Det betyr at vi som leger har et utvidet ansvar for utviklingshemmedes levekår. Dette gjelder fastleger, spesialister i andrelinjetjenesten, og særlig leger i offentlige stillinger, som kommunalråder, helsesjefer, fylkesleger og de såkalte helsetoppene i Helse- og omsorgsdepartementet og Helsedirektoratet.

\section{«Politikerne må slutte å snakke om likeverd og heller handle»}

Etter at denne kronikken ble innsendt første gang, har Helsedirektoratet publisert en ny veileder for gode helse- og omsorgstjenester til personer med utviklingshemming (31). Den kan være et godt sted å starte, selv om den ikke går langt nok i forhold til den internasjonale klassifikasjonen av funksjon, funksjonshemming og helse. Politikerne må slutte å snakke om likeverd og heller handle. En start vil være å rettighetsfeste intensjonene i ansvarsreformen i tråd med CRPD-konvensjonen. Det er en skam at denne gjennomtenkte og visjonære reformen, som altså hadde en lege som arkitekt, har havarert.

\section{LITTERATUR}

1. Søbye E. HVPU-reformen: Intensjoner og forløp. Samfunnsspeilet 1994; nr. 1: 32-5.

2. NOU 1973:25. Omsorg for psyksk utviklingshemmede: Målsetting og retningslinjer. https://www.nb.no/nbsok/nb/a5d6bc71ae6e89136bcabea6foo52565?lang=no\#51 Lest 21.5.2021.

3. NOU 1985:34 Levekår for psykisk utviklingshemmede. https://www.nb.no/items/69e686oa2oedca97a70a86451a340d5e? page $=$ o\&searchText=NOU\%201985:34\%20Levek\%C3\%A5r\%2ofor\%2opsykisk\%2outviklingshemmede Lest 21.5.2021. 
4. Fjermeros H. Åndssvak! Et bidrag til sentralinstitusjonens og åndssvakeomsorgens historie. Oslo: Universitetsforlaget, 2009.

5. International classification of functioning, disability and health (ICF). Geneva: World Health Organization, 2001. https://www.who.int/standards/classifications/international-classification-offunctioning-disability-and-health Lest 21.5.2021.

6. Konvensjon om rettighetene til mennesker med nedsatt funksjonsevne. Oslo: Barne-, likestillingsog inkluderingsdepartementet, 2013.

https://www.regjeringen.no/globalassets/upload/bld/sla/funk/konvensjon_web.pdf Lest 21.5.2021.

7. Kittelsaa A, Tøssebro J. Store bofellesskap for personer med utviklingshemming. Trondheim: NTNU Samfunnsforskning AS, 2011.

https://naku.no/sites/default/files/files/Store\%2obofellesskap_rapport.pdf Lest 21.5.2021.

8. NOU 2016:17 På lik linje. Åtte løft for å realisere rettigheter for personer med utviklingshemning. https://www.regjeringen.no/contentassets/bobaf226586543ada7c53ob4482678b8/no/pdfs/nou20162016 oo170oodddpdfs.pdf Lest 21.5.2021.

9. Syse A. Rettssikkerhet og livskvalitet for utviklingshemmete. Rettigheter, vern og kontroll som rettslige virkemidler. 1. utg. Oslo: Ad Notam Gyldendal, 1995.

10. Vik T. Utviklingshemmede i Europa. Paidos 2020;38: 160-3.

11. Weissmann G. Citizen Pinel and the madman at Bellevue. FASEB J 2008; 22: 1289-93. [PubMed] [CrossRef]

12. Skålevåg SA. Philippe Pinel. Store norske leksikon. https://snl.no/Philippe_Pinel Lest 21.5.2021.

13. Groff ML. Jean Marc Gaspard Itard. Psychol Clin 1932; 20: 246-56. [PubMed]

14. Ward OC. John Langdon Down: the man and the message. Downs Syndr Res Pract 1999; 6: 19-24. [PubMed][CrossRef]

15. Jacobsen N. Norsk rasehygiene. Nor Tannlegeforen Tid 2008; 118: 516-20.

16. Kyllingstad JR. Eugenikk. Store norske leksikon. https://sml.snl.no/eugenikk. Lest 21.5.2021.

17. Aas I. Hvordan kan samfundet beskytte seg mot åndssvake og sedelighetsforbrytere? Oslo: Olaf Norlis Forlag, 1932.

18. Söderfeldt B. Den gömda Kennedydottern - och synen på funktionsnedsättningar. Lakartidningen 2016; 113: D6R4. [PubMed]

19. Beddies T, Schmiedebach HP. "Euthanasie"-Opfer und Versuchsobjekte. Kranke und behinderte Kinder in Berlin während des Zweiten Weltkriegs. Medizinhist J 2004; 39: 165-96. [PubMed]

20. Brusevold IJ. Vipeholmstudiene: Store norske leksikon. https://sml.snl.no/Vipeholmstudiene Lest 21.5.2021.

21. Jakobsen T. Vi vil, vi vil, men får vi det til? Levekår, tjenestetilbud og rettssikkerhet for personer med utviklingshemning. Raport IS-1456. Oslo: Helsedirektoratet, 2007.

https://naku.no/sites/default/files/IS-1456_17307a.pdf Lest 21.5.2021.

22. Meld. St. 45(2012-2013). Frihet og likeverd. Om mennesker med utviklingshemming. https://www.regjeringen.no/no/dokumenter/meld-st-45-2012--2013/id731249/ Lest 21.5.2021.

23. Rettssikkerhet for utviklingshemmede. Oslo: Helsetilsynet, 2006.

https://www.helsetilsynet.no/globalassets/opplastinger/Publikasjoner/rapporter20o6/helsetilsynetra pport2_2006.pdf/ Lest 21.5.2021.

24. Nilsen O. Tung tids tale. Oslo: Samlaget, 2018.

25. Nilsen O. Yt etter evne. Få etter behov. Oslo: Samlaget. 2020.

26. Ystgaard HM. Den tause sønnen. Oslo: Spartacus, 2019.

27. Gabrielsen L. Entré. Oslo: Gyldendal, 2020.

28. Vaage LA. Syngja. Oslo: Oktober, 2012.

29. Concluding observations on the initial report of Norway: Committee on the Rights of Persons with Disabilities. Geneva: United Nations Digital Library, 2019.

https://digitallibrary.un.org/record/3848336 Lest 21.5.2021.

30. Piene B. Stortinget sier nei til å ta funksjonshemmedes rettigheter inn i loven. Adresseavisen 9.3.2021. https://www.adressa.no/nyheter/innenriks/2021/03/o9/Stortinget-sier-nei-til-\%C3\%A5-tafunksjonshemmedes-rettigheter-inn-i-loven-23618871.ece Lest 21.5.2021.

31. Helsedirektoratet. Gode helse- og omsorgstjenester til personer med utviklingshemming. https://www.helsedirektoratet.no/veiledere/gode-helse-og-omsorgstjenester-til-personer-medutviklingshemming Lest 9.7.2021. 
Publisert: 27. august 2021. Tidsskr Nor Legeforen. DOI: 10.4045/tidsskr.21.0428

Mottatt 22.5.2021, godkjent 10.8.2021.

(C) Tidsskrift for Den norske legeforening 2023. Lastet ned fra tidsskriftet.no 26. april 2023. 